\title{
Author's Note
}

Transliteration from the Russian follows the Library of Congress system. Exceptions in the main text include place names and names of people who broadly published in the English language (Joseph Brodsky, Yuri Glazov) or whose names are Russian renderings of foreign names with English-language analogues (Roy, Natalie). Names of certain well-known figures appear in their most familiar English-language form (Fyodor Dostoevsky, Leo Tolstoy).

Poetry that constitutes the main subject of analysis is quoted in the Russian original followed by English translation, while works that consist entirely or primarily of prose are quoted in the English alone. The sections of Venedikt Erofeev's play Walpurgis Night, or The Steps of the Commander in which the characters speak in iambic pentameter are thus treated as parts of a work of prose and presented only in English. Excerpts from Brodsky's poem "Gorbunov and Gorchakov" use quotation marks within square brackets to indicate speech that begins earlier or ends later than the given section. All translations into English are the author's own unless otherwise indicated. 
